\title{
DUAL-PURPOSE BLIND NAVIGATION BOX
}

\author{
M.Prem Kumar' ${ }^{1}$, Sandeep Reddy A.V ${ }^{2}$, Abid Hussain Zaidi ${ }^{3}$
}

\begin{abstract}
The combination of sensors and microcontrollers can be a boon for physically challenged population. Ultrasonic sensors have convincing features over other sensors. These sensors are widely used for range finding for indoor and outdoor applications in robotics. These sensors can be used along with microcontroller to sense the objects with the echoes principle. The proposed gadget has applications like obstacle detection and navigation; which can aid visually impaired individuals, who are unable to afford the service animals or hinge on other helpers for their regular walking or movements.
\end{abstract}

Keywords: Buzzer, Battery, DCmotor, Microcontroller, Ultrasonic sensor, Wheels, Wooden Stick ****

\section{INTRODUCTION}

The main objective of the amenity is to develop a smart portable Dual-purpose device which can assist to identify hindrances on its way and also to guide the unsighted person to move around without a helping hand [1]. Interfacing of microcontroller with sensors provides the ability to sense the environment and control the actuators required for recognizing the obstacles if any. This device can help the blind person to move in a room without approaching closely to the unknown objects and also work as a guiding tool to move from one place to another without much effort.

\section{WORK AND METHODS}

Ultrasonic sensor provides an easy method of distance measurement in contrast with the other sensors with comparison as shown in table.1.The chosen ultrasonic ping sensor is perfect for any number of applications that require performing measurements between moving or stationary objects. Ultrasonic measurements work in any lighting condition, making this a good choice to supplement infrared object detectors with very few limitations [3]. It is capable of spotting the obstacle within 1 meter range to detect obstacles and give a quick immediate output. Designing two separate units namely 1) Navigation Box Unit and 2) Motor Driving Unit can be a challenging task with innovative design considerations.

\subsection{Navigation Box Unit}

A Smart Navigation Box is constructed which is small, compact and tough in handling usage. The unit has microcontroller, buzzers, battery enclosed within a plastic packaging which is less in weight and easy to assemble the units shown in fig.3. The sensor can transmit the analog signals to the interfaced microcontroller, which has an inbuilt analog to digital converter. The microcontroller which comes in various sizes and specifications is opted to satisfy the requirements like cost, speed, and easiness to program, inbuilt ADC, small size, etc. An 8 bit microcontroller with $4 \mathrm{~K} \mathrm{ROM}$ and $1 \mathrm{~K}$ RAM is well enough to make this compact device which can work on a DC battery. The flow chart for programming the microcontroller is as shown in fig.2.The sensor identifies the barriers in the walking path and the microcontroller provides an audible beep with the help of a piezoelectric buzzer.

Interfacing to a microcontroller is a snap. A single I/O (InputOutput) pin is used to trigger an ultrasonic burst (well above human hearing) and then "listen" for the echo return pulse. The sensor measures the time required for the echo return, and returns this value to the microcontroller as a variable-width pulse via the same $\mathrm{I} / \mathrm{O}$ pin. It provides precise, non-contact distance measurements within a $2 \mathrm{~cm}$ to $1 \mathrm{~m}$ range.

The sensor interfaced microcontroller assembly is Navigation Box Unit also called as Dual-purpose box. The block diagram of Dual-purpose box is as shown in fig. 1 .The construction is less in weight, effortless and untroubled, portable structure providing an ease to fetch along with the needy ones.

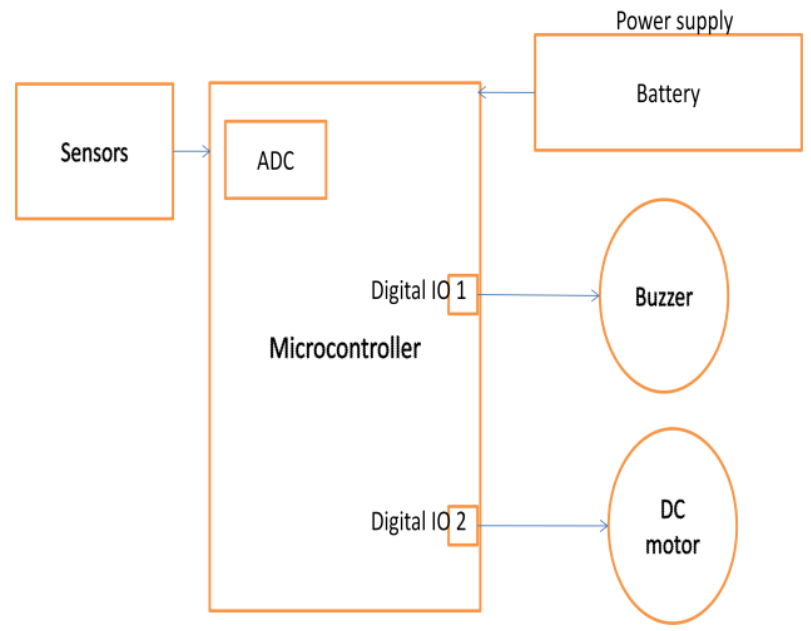

Fig. 1 Block Diagram of Dual-purpose Blind Navigation Box 


\subsection{Motor Driving Unit}

The microcontroller also with its digital output can drive the actuators with its $\mathrm{mA}$ currents. It provides enough current to drive a DC motor without the need of a motor driver IC. A separate motor driving unit is designed with a single DC motor and two balancing wheels as shown in the fig. 5 .When the Dualpurpose Box is docked to this unit; the controller senses the obstacles from the environment with the ultrasonic sensor and provides an output. This output is essentially an audio beep generated by a piezoelectric buzzer. An another output is generated when the dual purpose box is mounted on the motor driving unit attached to a wooden guiding stick which is commonly used by the impaired people. It drives the motor in the forward direction when there are no obstacles present in the walking path of the person holding the guiding stick as shown in the fig.7. Since holding a weight less stick is nothing new to the visually impaired people using this gadget attached stick helps them great fully. Any obstruction detected makes the motor stop immediately with a simultaneous buzzer sound, and then the individual handling the gadget will well understand to change his path direction.

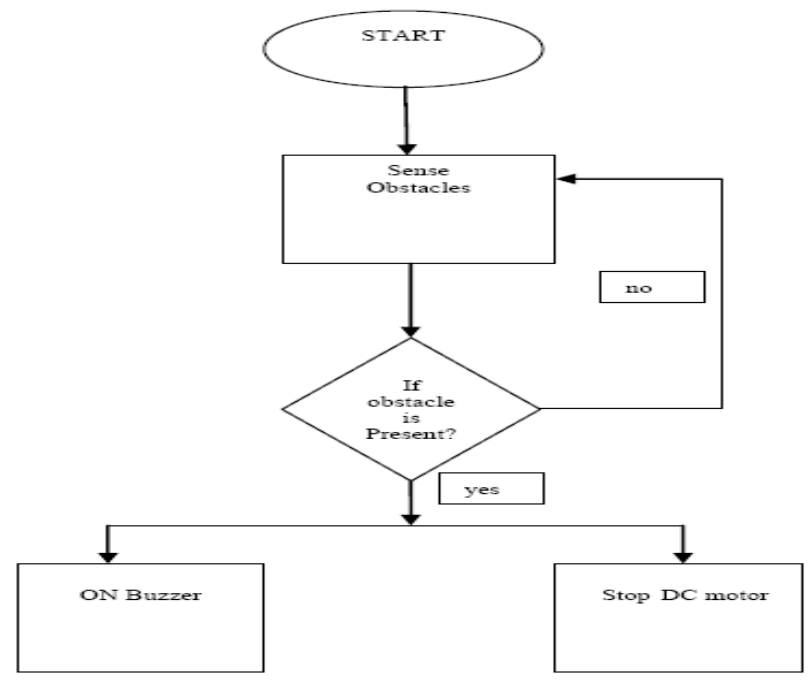

Fig.2 Flow chart for Dual -purpose navigation Box

Table 1 Comparison for various sensors

\begin{tabular}{|l|l|l|l|}
\hline Sensor & $\begin{array}{l}\text { Outdoor } \\
\text { performance }\end{array}$ & $\begin{array}{l}\text { Obstacle detec- } \\
\text { tion }\end{array}$ & Cost \\
\hline $\begin{array}{l}\text { Ultrason- } \\
\text { ic sensor }\end{array}$ & $\begin{array}{l}\text { Good } \\
\text { Temperature } \\
\text { and wind } \\
\text { mildly effect } \\
\text { data quality }\end{array}$ & $\begin{array}{l}\text { Good } \\
\text { Difficult to } \\
\text { detect obstacles } \\
\text { with curved } \\
\text { surfaces }\end{array}$ & $\begin{array}{l}\text { Excellent } \\
\text { Low cost } \\
\text { sensor }\end{array}$ \\
\hline Infrared & $\begin{array}{l}\text { Poor } \\
\text { Interference } \\
\text { from sun's } \\
\text { radiation }\end{array}$ & $\begin{array}{l}\text { Good Difficult to } \\
\text { detect reflective } \\
\text { and transparent }\end{array}$ & $\begin{array}{l}\text { Excellent } \\
\text { Low cont } \\
\text { sensor }\end{array}$ \\
\hline
\end{tabular}

\begin{tabular}{|l|l|l|l|}
\hline & $\begin{array}{l}\text { greatly de- } \\
\text { grade data } \\
\text { quality }\end{array}$ & $\begin{array}{l}\text { objects } \\
\text { Like mirrors } \\
\text { and glass win- } \\
\text { dows }\end{array}$ & \\
\hline LiDAR & $\begin{array}{l}\text { Excellent } \\
\text { Minimal } \\
\text { adverse ef- } \\
\text { fects asso- } \\
\text { ciated with- } \\
\text { out opera- } \\
\text { tion }\end{array}$ & $\begin{array}{l}\text { Good } \\
\text { Difficult to } \\
\text { detect reflective } \\
\text { and transparent } \\
\text { objects } \\
\text { like mirrors and } \\
\text { glass windows }\end{array}$ & $\begin{array}{l}\text { Expensive } \\
\text { sensor }\end{array}$ \\
\hline
\end{tabular}

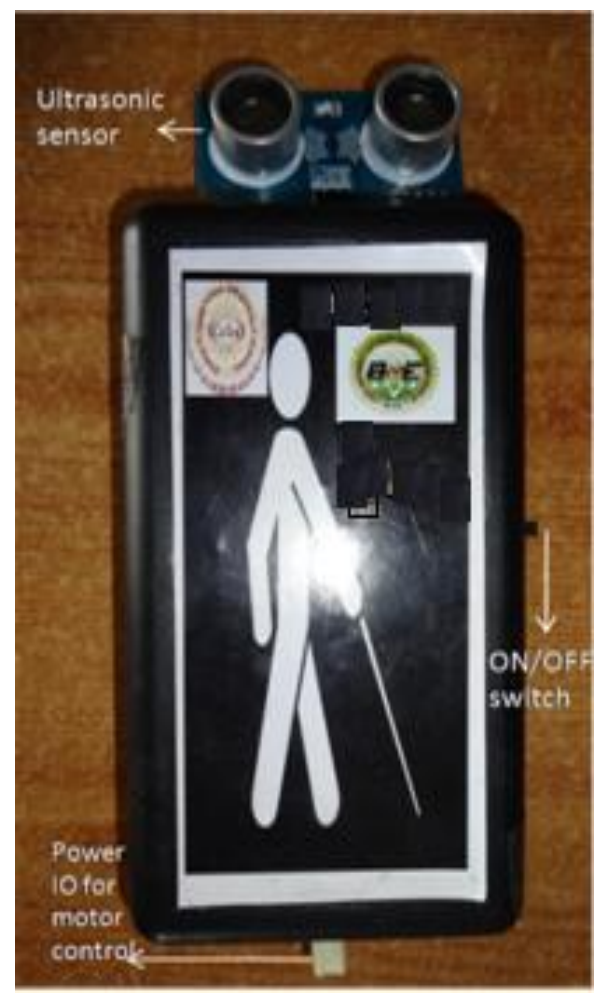

Fig. 3 Dual-purpose Blind Navigation Box unit

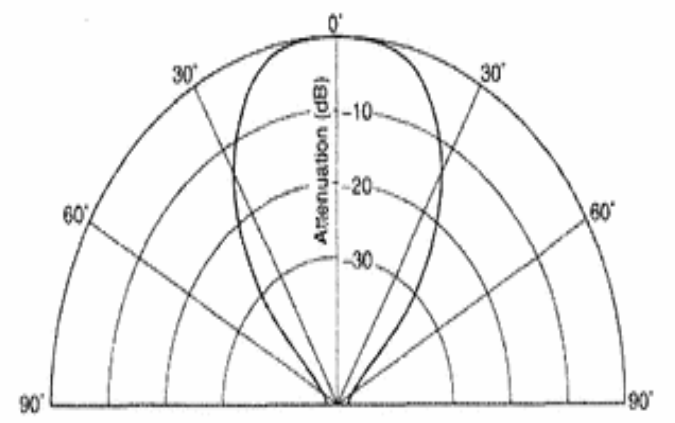

Fig. 4 Direction response of ultrasonic sensor 


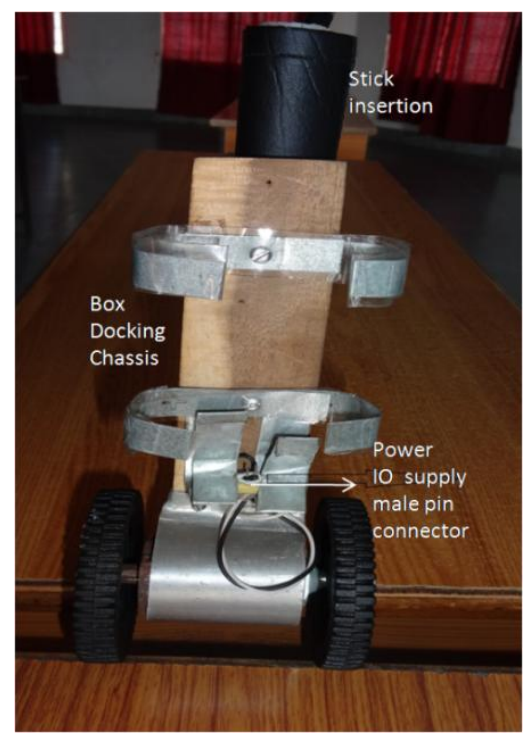

Fig.5 Motor driving unit

\section{RESULTS}

Dual-purpose blind navigation box was tested for obstacle detections without attaching to a motor driving unit as shown in fig.6. The sensor is agile for obstacle detection up to $1 \mathrm{~m}$ range and an angle up to 30 degrees from it centre as represented in fig.4.In the presence of obstruction, the device gave excellent audio output in the form of a beep, which acted as a quick indicator for the blind person. The box simply docked to the motor driving unit helped the blind to navigate in the forward directions. The motor stopped when an obstruction is sensed with a quick continuous buzzer sound. Then the device was turned manually by the user in other directions to walk in a clear environment. It requires some practice and knowledge to operate this system for regular use. The complete system operates on rechargeable $9 \mathrm{~V}$ that can last for 11 hours without motor driving unit and 4 hours with the motor driving unit.

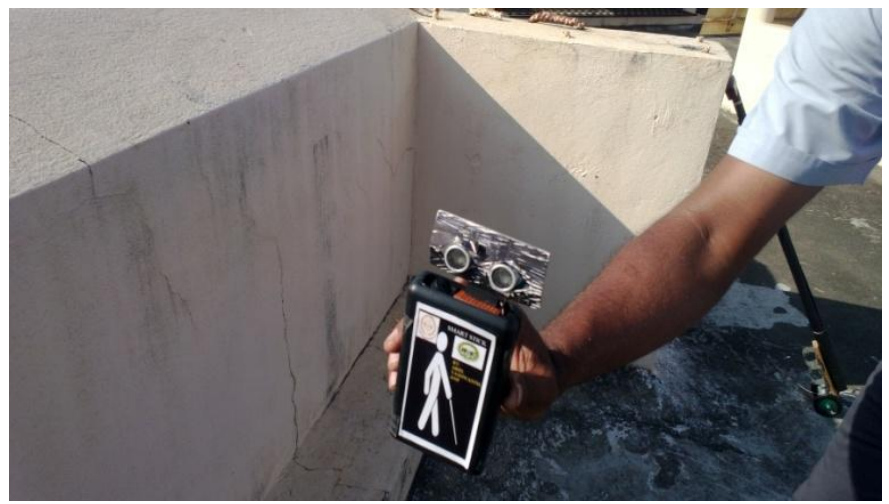

Fig. 6 Dual-purpose Blind Navigation Box used for Barrier Detections

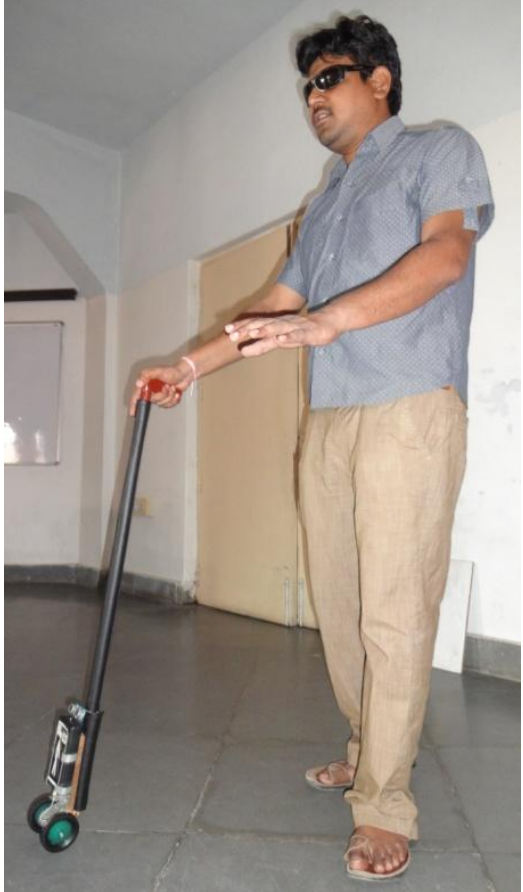

Fig.7 Dual-purpose Blind Navigation Box attached with the motor driving unit and stick is used to hold it.

\section{CONCLUSIONS}

We have developed a Dual-purpose portable box for blind navigation to detect the obstacles in the range of 1 meter.This range of detection can be extended considering the demand of the users. The device is excellent in indoor applications and also worked well for outdoor navigation in sunny and cold climate conditions. More features can be appended on this box to make it a multi-purpose box to control the appliances at home or office.

\section{ACKNOWLEDGMENTS}

We are thankful to GRIET and Department of Biomedical Engineering for their constant support and also for providing the laboratories and resources.

\section{REFERENCES}

[1] Sung Jae Kang, Young Ho, Kim, In Hyuk Moon, "Development of an Intelligent Guide-Stick for the Blind", Proceedings of the 2001 IEEE,Seoul, Korea. May 21-26, 2001, International Conference on Robotics \& Automation.

[2] Dong-Won Jung, Zhong-Soo Lim, Byung-Geuk Kim and Nak-Ku Kim, "Multi-Channel Ultrasonic Sensor System for Obstacle Detection of the Mobile Robot", International Conference on Control, Automation and Systems 2007 Oct. 17-20, 2007 in COEX, Seoul, Korea. 
[3] Johann Borenstein and Yoram Koren,"Obstacle Avoidance with Ultrasonic Sensors", Ieee Journal Of Robotics And Automation, Vol. 4, No. 2, April I988.

[4] B.Siciliano, O. Khatib: Springer handbook of Robotics, Wursburg: Springer (pp.492-493), (2008).

[5] D. P. Massa: Choosing an ultrasonic sensor for proximity or distance measurement Part 2: Optimizing sensor selection, Acoustic/ultrasound, sensorsmag, (1999).

[6] J. Borenstein, and I. Ulrich, "The Guidecane -A Computerized Travel Aid for the Active Guidance of Blind Pedestrians", International Conference on Robotics and Automation, pp. 1283-1288, 1997. 